Religare, ISSN: 19826605, v.14, n.1, agosto de 2017, p. 131-162.

\title{
O espiritismo nos livros didáticos de história: a diversidade religiosa em questão
}

\author{
Spiritism in didactic books of history: religious diversity in \\ question
}

André Victor Cavalcanti Seal da Cunha ${ }^{1}$

\section{Resumo}

Neste artigo buscamos refletir como a História escolar aborda o fenômeno religioso. Realizamos um mapeamento da diversidade religiosa apresentada nas obras didáticas, tanto na escala global quanto no âmbito nacional. Diante dos resultados, delimitei um segmento religioso específico presente na História pátria. Aprofundamos nossas reflexões acerca da História do Espiritismo. Como a História peculiar desta religião estaria aparecendo nos livros didáticos? Optamos tratar da problemática investigativa por uma abordagem qualitativa. Definimos como fontes impressas da pesquisa três coleções de livros didáticos de História, destinadas ao segundo segmento do ensino fundamental, publicadas nesta última década. Através do movimento das análises surgiram diversas inquietações. Nossa intenção foi montar um quadro que permitisse vislumbrar como o fenômeno religioso surge na trilha narrativa das coleções e mais especificamente como o Espiritismo aparece no cenário da diversidade religiosa brasileira. Identificamos lacunas existentes sobre a História dos diversos segmentos religiosos, bem como o silenciamento das múltiplas opções construídas no campo religioso brasileiro a partir do Império, mas principalmente do período republicano. Observamos assim que as coleções deixaram de explorar o potencial formativo que o estudo da diversidade religiosa sob o ponto de vista histórico poderia trazer. Não problematizaram ou secundarizaram o fenômeno religioso como objeto de estudo.

Palavras-Chaves: Espiritismo. Livro Didático. Diversidade Religiosa.

\footnotetext{
${ }^{1}$ Professor do Departamento de História do campus central da Universidade do Estado do Rio Grande do Norte. Professor do quadro permanente do Programa de Pós-graduação Interdisciplinar em Ciências Sociais e Humanas na mesma instituição. E-mail: andrevseal@yahoo.com.br
} 


\section{Abstract}

In this article we seek to reflect how the School History is approaching the religious phenomenon. I felt the need, in order to approach the object, to map the religious diversity presented in the works, both on a global scale and at the national level. Given the results, I delimited a specific religious segment present in the history of the country. I chose in this way, to deepen our reflections on the History of Spiritism. How would the peculiar history of this religion be appearing in textbooks? It was decided to deal with the research problem a qualitative approach. We have defined three collections of History textbooks for the second segment of elementary education published in the last decade as printed sources of the research. Through the analysis movement, there were several concerns. Our intention was to create a framework that would allow us to glimpse how the religious phenomenon appears in the narrative trail of the collections and more specifically how Spiritism appears in the scenario of Brazilian religious diversity. In the analysis exercise we identified existing gaps in the history of the various religious segments, as well as the silencing of the multiple options built in the Brazilian religious field from the Empire, but mainly from the Republican period. We have thus seen that the collections failed to exploit the formative potential that the study of religious diversity from the historical point of view could bring. They failed to take or seconded the religious phenomenon as an object of study.

Keywords: Spiritism. Textbook. Religious Diversity.

\section{Introdução}

"Uma História Muito Particular" foi o título da reportagem de capa da Revista Época, publicada em 24 de setembro de 2007. Nela, a coleção didática Nova História Critica, que havia desbancado a História e Vida Integrada da primeira posição em número de vendas ao Programa Nacional do Livro Didático (PNLD) na edição de 2003, fora acusada de maniqueísmo e doutrinação políticoideológica. Capitaneada por Ali Kamel, diretor de jornalismo da Rede Globo, que dias antes havia publicado em sua coluna trechos da obra referida, sucederam-se uma avalanche de reportagens na mass mídia nacional acerca de problemas nos 
livros didáticos de História. No caso "particular" da Nova História Crítica, coleção reprovada pela avaliação do MEC em 2006, a editora Nova Geração, responsável pela sua publicação, divulgou um material em resposta cujo título sugestivo foi "As Mentiras da Grande Imprensa", no qual denuncia as reportagens como campanha difamatória patrocinada pela "voracidade do capital estrangeiro". O texto foi finalizado com as seguintes palavras:

Nesta luta, que é de todos os brasileiros, contamos com professores e estudantes, pais de alunos e diretores de escolas. Avisamos: resistiremos à pressão! Continuaremos a denunciar a invasão do grande capital financeiro internacional. E para os grupos estrangeiros que descaradamente nos procuram para nos comprar, teremos sempre três palavras: Não, Não e Não!

O "assédio" referido como "invasão do grande capital", trata-se da entrada no mercado brasileiro na última década do século XX de editoras multinacionais atraídas pelas lucratividades advindas do maior programa público de compra de livros escolares do mundo: o já referido PNLD². Suas repercussões em diversos aspectos foram muito significativas, seja promovendo a formação de conglomerados editorias no setor de didáticos em nosso país, seja trazendo ao centro dos debates acadêmicos as pesquisas acerca dos livros didáticos, seja possibilitando uma reconfiguração na materialidade mesma das mais diferentes coleções, que ganharam colorações histórico-educacionais bastante diversificadas para atender os mais variados paladares de seu mercado consumidor.

Partimos assim da hipótese, transformada em pressuposto do artigo, que o livro didático de História vem passando por processos de reconfiguração durante esta última década. No seu bojo foram colocadas em movimento as complexas maquinarias dos jogos da memória, da redefinição de nossas referências históricas. Envolvendo sempre disputa, tomadas de decisão e relações

\footnotetext{
2 No caso do segundo segmento do ensino fundamental. As avaliações do primeiro segmento tiveram início em 1996.
} 
de poder. A reconfiguração das obras didáticas, alavancada pelo processo de avaliação do PNLD, compõe um capítulo no

“...conflito, nem sempre declarado, entre os que se vêem autorizados para legitimar o que deve ser contado e como se deve contar. E com o crescimento do mercado editorial, esse qüiproquó passa a ter outras engrenagens, que também não foram sistematicamente estudadas do ponto de vista historiográfico." (Ramos, 2008, 294).

O caso da coleção assinada por Mário Schmidt explicita bem a complexidade da guerra simbólica em jogo. Múltiplos interesses atuam quando tratamos da definição de quais conteúdos históricos escolares privilegiar. Interesses inclusive comerciais, pois a depender da configuração da obra, ela possuirá maior ou menor poder de vendagem. Não obstante, para além deste horizonte, compreendemos a repercussão que um material como este tem na formação de representações norteadoras de incontáveis gerações. Os livros didáticos de História têm assim alguma força transformadora.

Escolhi para discutir neste artigo um aspecto ainda pouco trabalhado pela literatura acadêmica. Há uma dimensão axiológica, valorativa no discurso histórico escolar. Se falamos a partir de um lugar, este lugar é pleno de nossos valores. Estes também marcam a forma como vemos o mundo, os outros e a nós mesmos. As memórias construídas não podem ser dissociadas das sensibilidades, dos afetos. Um campo que historicamente assumiu compromissos explícitos com a formação de valores é o campo religioso. Para este texto gostaria de inverter a proposição e refletir como a História escolar aborda a religião, sem perder de vista as possíveis contribuições que o estudo histórico do fenômeno religioso poderia trazer para o enriquecimento da dimensão axiológica dos educandos. 
Religare, ISSN: 19826605, v.14, n.1, agosto de 2017, p. 131-162.

Definimos como fontes impressas da pesquisa três coleções de livros didáticos de História, destinadas ao segundo segmento do ensino fundamental ${ }^{3}$, publicadas nas últimas décadas. A escolha das coleções remeteu a alguns critérios que precisamos explicitar. Primeiramente, a definição das obras ${ }^{4}$ justifica-se diante da impossibilidade de abarcar um volume maior para um recorte qualitativo, como o requerido pela investigação, pois a resposta a nossa pergunta “...deve ser buscada no plano da qualidade, não no brutalmente quantitativo" (GIZBURG, 2007, p.285). Em segundo lugar, foram escolhidas por serem representantes de propostas distintas para o ensino de História e trazem uma organização diferente das temáticas entre si.

A coleção Nova História Crítica, já referida, tratava-se de uma organização integrada, na qual narrativas da dita História Geral são intercaladas a saberes relativos à História do Brasil. Outra obra que integrou nosso corpo documental foi assinada por Guilherme Amaral e Gustavo Magalhães, intitulada simplesmente de História, integra a Coleção ELOS da editora IBEP. Está situada nas fronteiras da proposta de História temática, cuja característica principal é a de organizar as narrativas a partir de eixos temáticos e não exclusivamente cronológicos ou geopolíticos. Compondo ainda as fontes impressas da investigação, tivemos a coleção Aprendendo com a História, também da IBEP, sob a responsabilidade técnica de Francisco Teixeira. Esta última caracterizou-se por ser uma representante da tradição. Foi configurada na perspectiva dos círculos concêntricos ${ }^{5}$, tendo os dois primeiros anos dedicados a História do Brasil e seu segundo seguimento abordando a História dita Geral.

\footnotetext{
${ }^{3}$ Este é o nível de maior atuação do Estado na compra de Livros. As obras de História destinadas ao ensino médio passaram a ser compradas em 2006.

4 O MEC considera hoje uma "obra didática" para o segundo segmento do ensino fundamental, o conjunto dos quatro livros da coleção.

${ }^{5}$ Abordagem dominante no ensino de História durante o tecnicismo pedagógico da década de 1970. Preconizava que o próximo espacial seria equivalente ao próximo cognitivo. Dentro desta compressão, por exemplo, a História do bairro seria mais facilmente aprendida do que a História do Brasil, portanto a primeira deveria anteceder a segunda na organização das narrativas.
} 
Religare, ISSN: 19826605, v.14, n.1, agosto de 2017, p. 131-162.

Através do movimento das análises surgiram diversas inquietações. Optamos por estabelecer níveis de análise e recortes mais precisos. Realizamos um mapeamento da diversidade religiosa apresentada nas obras, tanto na escala global quanto no âmbito nacional. Diante dos resultados, delimitamos um segmento religioso específico presente na História pátria. Visamos com este recurso, verticalizar o olhar investigativo, bem como demonstrar o fosso existente entre uma produção acadêmica de fôlego e o silêncio nos livros didáticos com relação à variedade de movimentos religiosos presentes no Brasil. Procuramos então uma fundamentação em autores que escreveram sobre nossa História da religião. Descobrimos em Arribas (2010) o papel desempenhado pelo Espiritismo ${ }^{6}$ na construção da diversidade religiosa brasileira. Com sua inserção, desde meados do século XIX, ocorreram fortes debates que contribuíram para desmonopolizar os bens de salvação no campo religioso nacional (ARRIBAS, 2010, 20-21). Aprofundamos nossas reflexões acerca da História da Doutrina Espírita. Como a História peculiar deste movimento estaria aparecendo nos livros didáticos? Nossa intenção foi montar um quadro que permitisse vislumbrar como o fenômeno religioso surge na trilha narrativa das coleções e mais especificamente como o Espiritismo aparece no cenário da diversidade religiosa brasileira.

\section{Reflexões acerca do Livro Didático de História}

\footnotetext{
${ }^{6}$ Segundo Arribas $(2010,17)$ grande parte da produção acadêmica nas ciências humanas usa o termo espiritismo para designar diferentes segmentos religiosos e campos de práticas muito diversas entre si, lançando mão apenas do recurso da adjetivação para a sua distinção. Para ela, muitos autores se apropriam da categoria em foco sem refletir sobre o percurso histórico de sua construção. Como demonstra Arribas, atores sociais ligados à igreja católica e ao campo médico, desde o século XIX no Brasil, procuraram como estratégia de combate, associar o espiritismo aos cultos africanos e às práticas de charlatanismo visando desqualificar a doutrina espírita. Segmentos religiosos como o candomblé e a umbanda adotaram o rótulo de espiritismo buscando driblar a repressão policial e se qualificar diante da ação do estado brasileiro. Neste trabalho procuramos não cair nas armadilhas desta complexa teia semântica. Volvendo a acepção original do termo, o conceito de espiritismo "será sempre utilizado para designar o corpo teóricodoutrinário criado inicialmente por Allan Kardec, pseudônimo do pedagogo francês Hippolyte Léon Denizard Rivail (...)" (ARRIBAS, 2010, 17). Já que o próprio vocábulo representa um neologismo de autoria de Kardec, a ele recorreremos pela necessidade de delimitação.
} 
Sentimos a necessidade nesse artigo de uma instrumentalização teórica que nos permitisse possuir cada vez mais inteligibilidade e compreensão acerca do livro didático, ou seja: procuramos compreender este complexo artefato cultural. Alguns trabalhos foram centrais para nos nortear sobre este objeto denominado de livro didático de História. Um deles foi Gatti Júnior (2004). O autor estudou o processo de constituição dos livros didáticos contemporâneos. Seu recorte se deu entre as décadas de 70, 80 e 90, mais especificamente até 1997, ano de defesa do trabalho que lhe conferiu o doutoramento na PUC de São Paulo. Uma contribuição interessante de sua tese foi demonstrar a sofisticação do processo produtivo do livro didático no período em foco. Durante o momento estudado as editoras brasileiras passaram de empresas familiares, muitas funcionando em instalações precárias, a instituições privadas com sólido capital e portadoras de um parque editorial considerável. De solitárias máquinas off-set a computadores em rede já no final da década de 1980. Do trabalho quase que artesanal de um todo-poderoso autor a uma equipe técnica responsável, contando com uma complexa cadeia de divisão de tarefas. O autor permanece, embora como operário do texto, cuja proletarização será intensificada na primeira década do século vindouro. Consolidaram-se as figuras do editor e do copydesk no subsetor de didáticos. Hoje toda esta estrutura maturou. Nos grandes conglomerados editorias temos o funcionamento desta engrenagem, orquestrada pelo editor-chefe, mas com uma divisão hierárquica e especialização surpreendentes. Trabalhando de forma concatenada e até mesmo simultânea, uma equipe (e existem várias nas grandes editoras) elabora uma coleção, possuindo um ou mais responsáveis pela escrita do texto principal, auxiliados por especialistas em iconografia, em proposição de atividades, no tratamento da linguagem e principalmente, todos estes dirigidos pelo editor de área, com formação na disciplina que o livro didático aborda.

Segundo Gatti Júnior, no período anterior, compreendido entre os anos 30 e 60 do século XX, a produção didática possuía algumas características peculiares. Os LD's não representavam o produto 
Religare, ISSN: 19826605, v.14, n.1, agosto de 2017, p. 131-162.

principal quanto à vendagem das poucas editoras que se dedicavam a sua produção. Seus autores eram figuras de espaços considerados da "alta cultura". Não havia uma preocupação manifesta com o processo de ensino, o que resultavam, por exemplo, em uma falta de adequação entre a linguagem utilizada e o público a que a obra se destinava. Seu mote seria a erudição demonstrada. Desta forma, os manuais permaneciam durante muitos anos e até décadas inteiras sem sofrerem alterações (2004, p. 37).

Já no período do pós-1970, mas principalmente a partir dos anos de 1980 - ocorreu um crescimento vertiginoso do consumo de LD's no país. O que lançou o setor dos didáticos para o topo das vendas do mercado editorial nacional. Essa expansão levou a uma necessidade, para o atendimento da demanda crescente, de sofisticação do processo produtivo. Passou-se do autor individual à equipe técnica responsável, "de uma produção praticamente artesanal a uma produção em escala industrial, com a implantação de uma poderosa indústria editorial" (GATTI JUNIOR, 2004, p. 43-44).

Com a expansão do consumo e consequente complexificação da produção, os autores passaram a trabalhar agora com todo um grupo de profissionais técnicos qualificados, principalmente em parceria com editores especializados. Estes representavam uma estrutura organizacional multifacetada, cuja teia hierarquizada os situa, muitas vezes, em espaços marginais em relação ao epicentro do poder nas instituições. Este verdadeiramente é ocupado pelos editores, sujeitos todo-poderosos do mundo da edição. Desempenham a função de filtro, juiz, representando uma barreira intransponivel entre o manuscrito de um autor e seu público ou ponte que permite transformar um autor desconhecido em escritor consagrado (BRAGANÇA, 2005, p.224).

É neste lugar de decisão e de comando, e de criação, que está o coração do trabalho de editor. É também esse lugar que exige dele saberes específicos (escolher, fabricar, distribuir), que o diferenciam dos demais agentes envolvidos no processo editorial, e lhe impõe responsabilidades únicas, profissionais, sociais, econômicas, financeiras, administrativas e mesmo 
Religare, ISSN: 19826605, v.14, n.1, agosto de 2017, p. 131-162.

(juntamente com os autores) judiciais (BRAGANÇA, 2005, p. 224).

Os editores assim (geral e de área, no caso dos didáticos) desempenham função estratégica na mediação cultural de invenção de uma obra, pois criam fórmulas para "associar repertório textual e capacidade produtiva" (CHARTIER, 2002, p. 75).

Retomando Gatti Júnior, vemos que nos anos noventa, os livros didáticos se consolidaram enquanto uma mercadoria de alta vendagem, alcançando cifras até então nunca atingidas. Ao mesmo tempo, representaram para as editoras um negócio extremamente arriscado, pela competitividade enfrentada, contando com o emprego de marketing estratégico bastante agressivo e custoso, bem como pela especialização que passa a ser exigida dos profissionais envolvidos, resultando na formula: altos investimentos para a contratação cada vez em maior número de pessoal qualificado, somada ao retorno incerto ou nada garantido (GATTI JUNIOR, 2004, p. 45).

Um fenômeno que explicita bem a hiperespecialização requerida a esses sujeitossociais é o da profissionalização dos autores. Em aparente contradição com o papel "relativamente" secundário que passaram a desempenhar, ocorreu um aumento significativo das exigências para realizar esta função. Ao assinar uma coleção o autor torna-se uma marca, engendrando a solicitação de tempo e energia para o atendimento a um sem número de atividades, relativas principalmente à divulgação do seu produto, tais como: palestras, seminários, cursos e oficinas. Isso para não nos referirmos às estritamente relacionadas com a escrita e reescrita do texto propriamente dito. No trecho a seguir, Gatti Júnior sintetiza os eventos comentados:

Do ponto de vista editorial, o final da década de 1990 era palco do aumento da velocidade da elaboração e renovação das coleções, com consequente mudança da atuação dos autores de livros didáticos de História, que eram cada vez mais solicitados a exercerem atividades de divulgação de suas próprias coleções e, sobretudo, de revisão constante dos textos, com o 
Religare, ISSN: 19826605, v.14, n.1, agosto de 2017, p. 131-162.

aparecimento da tendência em contratar redatores profissionais para diminuir o trabalho desses autores (Ibidem, p. 139).

Hoje chegamos à velocidade de atualização de cerca de três anos em média, tempo este relativo à vida útil de uma publicação. Vêm destacando-se neste processo a figura destes "redatores profissionais", os chamados copydesks. Integrantes desta sofisticada rede de divisão de trabalho, composta por figuras responsáveis pela diagramação, ilustração, pesquisa iconográfica, revisão, edição de arte, etc., eis que ganha centralidade nestes novos tempos, a função da copydeskagem. Esta não deve ser reduzida à correção gramatical do texto, pois envolve todo um tratamento reinventivo na linguagem que o conforma (Munakata, 1997, p. 88-91; Munakata 2003, p. 275-276).

Todo esse processo de complexificação e hiperespecialização da produção de didáticos materializou-se em transformações significativas quanto à estrutura dos livros, que inclusive resultaram ao final dos noventa, em uma formatação padrão consolidada ${ }^{7}$. Não obstante, a complexidade do livro didático não se revela apenas na sua natureza - caracterizada por ser um objeto da indústria cultural - ou através do seu processo de criação, mas também em suas múltiplas funções. Mas o que é afinal um livro didático? Os mais variados sujeitos, envolvidos na sua cadeia inventiva (da produção ao uso) poderiam trazer representações advindas de suas múltiplas facetas. Seriam os livros então um produto da indústria cultural, portanto uma mercadoria. Seriam também um repositório de visões de mundo ou até de ideologias se quisermos nostalgicamente relembrar as análises da década de oitenta. Outra representação possível seria a de instrumento pedagógico, organizador de práticas de ensino. Diríamos que estes elementos compõem a pluralidade da natureza multifacetada dos LD's. Mas em um nível soberano, não poderíamos deixar de considerá-lo enquanto um artefato cultural, pois produz significado, significação e sentido.

\footnotetext{
${ }^{7}$ Impressos a quatro cores, os LD's destinados ao nível fundamental adquiriram o formato de $21 \mathrm{X}$ $28 \mathrm{~cm}$ e os voltados para o ensino médio, ficaram com $17 \mathrm{X} 23 \mathrm{~cm}$. Respectivamente, ganharam o máximo de páginas de 200 e 300 folhas. (Gatti Júnior, 2004, p. 140).
} 
Religare, ISSN: 19826605, v.14, n.1, agosto de 2017, p. 131-162.

Desta forma, assumimos o entendimento de que um livro didático não é apenas um objeto material inerte e sem vida (papel e tinta), mas um evento discursivo, materializando práticas discursivas plurais. Ele é, portanto, um integrante do mundo da cultura, possuindo um circuito cultural que o singulariza.

No Brasil, este circuito cultural que constitui o livro didático vem recebendo intervenções estatais através das avaliações do PNLD (Programa Nacional do Livro Didático). Realizado a partir de 1996, o processo avaliativo vem sendo apontado por especialistas como um ponto de inflexão na história da produção didática (BATISTA E ROJO, 2005, p. 25). Esta situação se explica porque o Estado brasileiro representa na atualidade o comprador privilegiado das editoras. Obviamente que os critérios utilizados pelo programa, explicitados no edital de convocação das inscrições e presentes na estrutura das fichas de avaliação dos pareceristas, representam uma forte referência ao setor. Vemos assim a complexidade da teia discursiva criadora da produção didática, engendrada através da "complicada inter-relação entre as políticas de adoção de livros didáticos do Estado e o mercado editorial que publica esses livros" (APPLE, 2006, p. 63).

Para remontar este processo, estamos nos ancorando na tese de Cassiano (2007). Em sua investigação a autora relaciona os dois momentos do Programa Nacional do Livro Didático (PNLD) com a expansão do setor de didáticos do mercado editorial no Brasil. Para citarmos algumas cifras, já em 1987, ano de criação do PNLD, em substituição ao PLIDEF (Programa do livro didático/ensino fundamental), a compra de livros didáticos pelo governo federal para distribuição gratuita às escolas em todo o território nacional passa de 12 para 55 milhões de exemplares. Como pode ser observado, o PNLD já nasceu gigante, sendo o maior programa público de compra de livros do mundo, representou na época a aquisição pelo governo federal de cerca de $70 \%$ da produção de livros didáticos no país (CASSIANO, 2007, p. 29). 
Religare, ISSN: 19826605, v.14, n.1, agosto de 2017, p. 131-162.

Vemos assim que a entrada em cena do Estado brasileiro como comprador privilegiado foi peça fundamental para explicar o processo, estudado por Gatti Júnior, de crescimento das editoras e a complexificação da produção de didáticos. Com a massificação da educação, implementada de forma mais consubstancial inicialmente durante a ditadura civil-militar de 1964, mas concretizada nas décadas de 1980 e 1990, a produção de livros didáticos passa a representar um grande negócio para o mercado editorial. Foi esta primeira fase do PNLD que forneceu as bases materiais para transformar o setor, marcado agora pela disputa acirrada, pela competição entre grandes editoras.

Segundo Cassiano, este segundo momento pode ser delimitado partir de 1995. Durante o governo FHC foram definidas medidas que alteraram substancialmente a atuação do PNLD. Primeiramente definiu-se para programa uma fonte financiadora perene e estável: o Fundo Nacional de Desenvolvimento da Educação (FNDE). Assim foi estruturada a universalização da acessibilidade dos livros, que paulatinamente passaram a incluir um número maior de disciplinas escolares. Mas a guinada significativa deveu-se a instauração do processo de avaliação das obras a serem compradas. Deste então, equipes de profissionais considerados especialistas foram reunidas pelo MEC para a realização desta tarefa. São, em sua maioria, professores universitários com atuação e pesquisas na área específica abordada pelo livro ou no ensino da disciplina de que trata a coleção. Só os livros indicados por esses avaliadores passaram a ter possibilidade de serem escolhidos pelos docentes. Apenas as obras aprovadas para serem inseridas no catálogo, distribuído aos professores sob a denominação de "Guia do Livro Didático", poderiam ser compradas pelo Estado brasileiro. Esta modificação pode ser considerada a mais significativa porque representa uma intervenção direta do Estado, mesmo que autodenominada não-diretiva ou não-prescritiva, sobre a qualidade das obras e os conteúdos nelas presentes. De acordo com Cassiano (2007), um desdobramentos acarretados pelo aumento ainda maior nas compras dos livros 
Religare, ISSN: 19826605, v.14, n.1, agosto de 2017, p. 131-162.

nesta segunda fase de Programa foi a entrada de grupos editoriais multinacionais no mercado brasileiro e a formação de conglomerados empresariais nacionais. Na última década quatro empresas produtoras de didáticos consolidaram-se enquanto os maiores índices de faturamentos anuais do nosso mercado editorial. Foram elas: a Ática, a FTD, a Saraiva e a Moderna. Destas, apenas a FTD não foi comprada por editoras estrangeiras ou com capital internacional, sendo a editora Moderna adquiridas pela editora Santilhana, pertencente ao grupo espanhol dono do jornal El Pais (CASSIANO, 2007, p. 11).

Vale salientar que esta relação não é nova. O percurso dos livros didáticos no Brasil demonstra serem estes uma mercadoria disputada por editoras de âmbito nacional e global e que vêm sofrendo constantes intervenções do Estado (BITTENCOURT, 2010, p. 545-547; LUCA, 2009, p. 171-171) Não obstante, nesta segunda fase do PNLD, a ampliação do programa atraiu para o Brasil empresas multinacionais interessadas nos vultosos lucros proporcionados pela compra governamental. Patrocinada pelo Estado, tivemos a transformação de empresas nacionais em conglomerados com a participação de capital estrangeiro, bem como a concentração dos recursos destinados para o programa a um número cada vez mais seleto de editoras.

\section{O Fenômeno Religioso nos Livros Didáticos de História: o que nos revelou o mapeamento?}

Realizamos então, uma leitura flutuante, optando por uma visão panorâmica, de superfície, buscando pinçar ocorrências de maior potencial elucidativo que nos permitissem exemplificar ou fundamentar as reflexões. Não há, portanto, uma pretensão de generalização. Buscamos a construção de um texto via triangulação: inventado na tessitura trançada entre autores acadêmicos e dados empíricos colhidos em nossas fontes. Para a análise das fontes impressas construí dois quadros. Um dedicado a sistematizar as temáticas por coleção das narrativas com o recorte na História do Brasil. No outro, inserimos as abordagens 
Religare, ISSN: 19826605, v.14, n.1, agosto de 2017, p. 131-162.

de âmbito geopolítico com a delimitação na dita História Geral. Mas afinal, o que nos revelou o olhar de sobrevôo? Comecemos pelo mais amplo:

TABELA 1 - TEMAS RELIGIOSOS NA HISTÓRIA GERAL

\begin{tabular}{|c|c|}
\hline Nova História Crítica & Temática de Âmbito Geral \\
\hline Livro 01 & $\begin{array}{l}\text { Abordagem da Evolução das Espécies e } \\
\text { da Evolução Humana p. } 38 \text {-55; } \\
\text { Hebreus - abordagem histórica p. 105- } \\
\text { 109; } \\
\text { Religião Persa p. 113; } \\
\text { Hinduísmo e Budismo p. 119- 121; } \\
\text { Confucionismo p. 127; } \\
\text { Religião Grega p. 144-145; } \\
\text { Religião Romana p. 178; } \\
\text { História do Cristianismo em Capítulo } \\
\text { Específico p. 196 -205; } \\
\text { Islamismo p. 216-119; } \\
\text { Igreja Ortodoxa Grega p. 235-238; } \\
\text { AS Cruzadas p. 252-253; } \\
\text { Cultura Medieval e a Igreja Católica p. } \\
\text { 262-263. }\end{array}$ \\
\hline Livro 02 & $\begin{array}{l}\text { Religião dos Povos Pré-colombianos } \\
\text { (ênfase nos sacrifícios humanos) p. 136; } \\
\text { Antropofagia dos Povos Pré-Cabralinos } \\
\text { p. 140; } \\
\text { Reformas Protestante e Católica p. } 162 \\
\text { 171; } \\
\text { Inquisição p. 170-171; } \\
\text { Islamismo na África p. } 178 .\end{array}$ \\
\hline Livro 03 & - \\
\hline Livro 04 & $\begin{array}{l}\text { Breve Referência a Luther King (Em uma } \\
\text { pergunta) p. } 257 .\end{array}$ \\
\hline História - Coleção Elos & Temática de Âmbito Geral \\
\hline Livro 01 & $\begin{array}{l}\text { Criacionismo versos Evolucionismo p. } \\
\text { 50-51; } \\
\text { Religião articulada ao Estado no Egito } \\
\text { Antigo p. 76-77, 83, 87(atividade); } \\
\text { Deuses Gregos p. } 107 \text { (Parágrafo), p. } 108 \\
\text { (box), p. } 113 \text { (atividade); } \\
\text { Deuses Romanos p. } 131 \text { (parágrafo); } \\
\text { Cristianismo como religião oficial do } \\
\text { Estado Romano p. 131 (Pergunta); } \\
\text { Igreja Medieval p.144-145; } \\
\text { Inquisição medieval p. 145; }\end{array}$ \\
\hline
\end{tabular}


Religare, ISSN: 19826605, v.14, n.1, agosto de 2017, p. 131-162.

\begin{tabular}{|c|c|}
\hline & Islamismo p. 155-168. \\
\hline Livro 02 & $\begin{array}{l}\text { Reforma Protestante e Contrarreforma } \\
\text { Católica p. 94-104; }\end{array}$ \\
\hline Livro 03 & 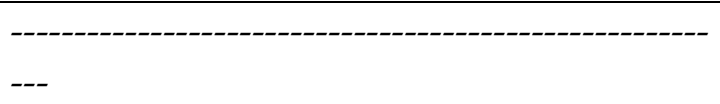 \\
\hline Livro 04 & $\begin{array}{l}\text {-------------------------------------------------------------- } \\
\text {--- }\end{array}$ \\
\hline Aprendendo com a História & Temática de Âmbito Geral \\
\hline Livro 01 & 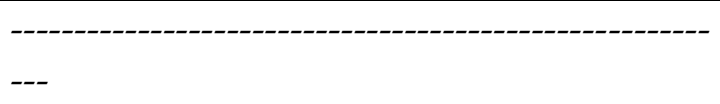 \\
\hline Livro 02 & 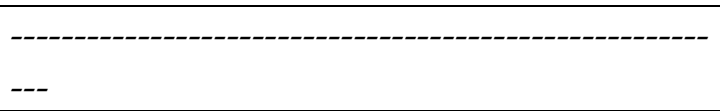 \\
\hline Livro 03 & $\begin{array}{l}\text { Abordagem evolucionista como teoria p. } \\
\text { 06-07; } \\
\text { Criacionismo versos evolucionismo (Box) } \\
\text { p.14; } \\
\text { Religião do Egito Antigo p. 73-75; } \\
\text { Religião dos Povos Pré-Cabralinos p. 86- } \\
\text { 87; } \\
\text { Hebreus - abordagem Bíblica p. 98-99; } \\
\text { O cristianismo em Roma p. 131 e 136-137; } \\
\text { Islamismo p. 170-182; } \\
\text { Cruzadas p. 192-199; } \\
\text { Fé e Razão no Pensamento medieval p. } \\
\text { 216-217. }\end{array}$ \\
\hline Livro 04 & $\begin{array}{l}\text { Breve referência ao Concílio Vaticano II } \\
\text { p. 22; } \\
\text { Reforma Protestante e Contrarreforma } \\
\text { Católica p. 24-26; } \\
\text { Função ideológica dos Jesuítas no } \\
\text { mundo colonial espanhol p. } 103 .\end{array}$ \\
\hline
\end{tabular}

Elaboração do próprio autor

Encontramos nas coleções a existência de temas canônicos relacionados de alguma forma ao campo religioso. Apesar das obras analisadas possuírem propostas diferentes de ensino de História, o quadro dos assuntos que abordam o fenômeno religioso demonstra diversas convergências nas trilhas narrativa seguidas, contando inclusive com temáticas convencionadas como "clássicas". Dentre outras, nas três estão presentes o debate entre a ciência e certos setores religiosos que questionam a evolução das espécies, a apresentação da religião na antiguidade, as cruzadas, a inquisição e finalmente as reformas religiosas do 
Religare, ISSN: 19826605, v.14, n.1, agosto de 2017, p. 131-162.

início da modernidade. Mas como abordagens de ensino de História tão diferentes possuem tantas semelhanças no percurso discursivo? Seguiriam elas a mesma orientação ideológica?

Munakata (1997) nos aponta alguns caminhos para possíveis respostas. Uma noção trazida pelo autor nos chamou particularmente a atenção pela contribuição elucidativa refere-se à convergência existente entre as trilhas narrativas das mais diversas coleções em diferentes editoras. Mesmo com a complexificação no seu processo de produção, os LD's de História avançavam pouco em termos do que havia se convencionado serem os objetos de estudo da História escolar e seus métodos de ensino-aprendizagem. Salvo as mudanças na sua estrutura material e a inserção da abordagem marxista nas narrativas ditas tradicionais, novos objetos e metodologias, que caracterizaram a efervescência do período no campo historiográfico e pedagógico, não apareciam de forma significativa. Munakata nos brinda aqui com a noção de "consenso do mercado". Há de fato um consenso na produção do setor de didáticos prevendo o que deve estar presente nos livros, representando uma espécie de currículo oculto, subterrâneo e soberano, com força, portanto, de prescrição.

Afirma o autor que a ideologia das editoras é o mercado. O livro didático é um produto da indústria editorial, uma mercadoria, e como toda mercadoria, se quer vendável para possibilitar a lucratividade. Desta forma, esta cultura histórica escolar materializada nas obras é engendrada na íntima relação com a busca por atender as expectativas dos seus consumidores diretos. Se os professores escolhem mais os livros com narrativas históricas ditas tradicionais, peroladas ao verniz de um marxismo tridentino e panfletário, serão conteúdos nesta perspectiva os inseridos.

Essa noção - do mercado enquanto orientação ideológica das editoras nos fornece uma chave explicativa para elucidar, pelo menos em parte, a relativa convergência acerca dos assuntos relacionados ao fenômeno religioso, bem como a existência de temáticas clássicas já convencionadas. Em um campo marcado por 
Religare, ISSN: 19826605, v.14, n.1, agosto de 2017, p. 131-162.

fortes disputas simbólicas é provável que as equipes técnicas responsáveis pela produção dos livros considerem arriscado inovar.

Outro dado interessante que pôde ser identificado pelo mapeamento realizado foi a concentração do tratamento dos assuntos relacionados ao campo religiosos no volume das obras dedicado ao surgimento das civilizações antigas, bem como a inexistência em livros inteiros da abordagem de temáticas oriundas do campo da história das religiões. Desta forma, grande parte do estudo histórico do fenômeno religioso se dá na perspectiva das origens. Após a explicação do surgimento, a religiosidade e as religiões desaparecem no vácuo. Como pôde ser observado no quadro apresentado, nas coleções Nova História Crítica e História da Elos o maior quantitativo de conteúdos são abordados nos livros direcionados ao sexto ano do ensino fundamental. Como segue a perspectiva do círculo concêntrico, a obra Aprendendo com a História inverte a ordem, mas mantém a lógica, sendo os mesmos temas estudados no oitavo ano.

Consideramos assim que a configuração das coleções analisadas pode dificultar - na esfera da recepção - a compressão histórica dos leitores sobre os movimentos religiosos, pois deixam de apresentar a dinâmica histórica da permanente construção das religiões e das religiosidades. Mostradas em momentos estanques, reduzidas ao estudo das origens, sem os seus diálogos, sem migrações constantes entre os rótulos, sem interlocuções e disputas estabelecidas entre os diferentes segmentos religiosos, sem as transformações ao longo do tempo, deixa-se de explorar a potencialidade que o tratamento desses conteúdos poderia trazer a uma formação para a diversidade, para o encontro como outro, para o respeito à diferença como um valor, como algo saudável e inerente a uma ética republicana.

Mesmo com o consenso do mercado, tratar e inovar em assuntos relacionados aos interesses religiosos e as sensibilidades inerentes as temáticas deste tipo permanece problemático. Mesmo com o consenso do mercado entorno de quais narrativas históricas escolares ensinar, incluindo-se que temáticas 
Religare, ISSN: 19826605, v.14, n.1, agosto de 2017, p. 131-162.

envolvendo aspectos relacionados às manifestações religiosas abordar, permanecem questionamentos a conteúdos canônicos, a assuntos clássicos, debatidos há décadas e que voltam a agenda de discussão. Este é, por exemplo, o caso da polêmica sobre a evolução das espécies. Não obstante, a configuração produzida pelo mercado ao que parece funciona bem em outros conteúdos semelhantes, já que são alvo de disputa permanente dos movimentos religiosos e não foram questionados por ninguém. É inquietante que não se tenha questionado nada desde 2004 acerca da reforma ou o papel da igreja no Brasil. E mais ainda, surpreendente quando se trata de um país com tamanha diversidade religiosa. Centremos nosso olhar no quadro relativo aos temas religiosos tratados na História do Brasil:

TABELA 2 - TEMAS RELIGIOSOS NA HISTÓRIA DO BRASIL

\begin{tabular}{|c|c|}
\hline Nova História Crítica & Temática de Âmbito Nacional \\
\hline Livro 01 & 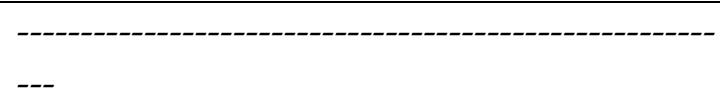 \\
\hline Livro 02 & 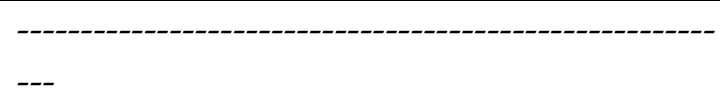 \\
\hline Livro 03 & $\begin{array}{l}\text { Questão Religiosa na Transição do } \\
\text { Império para a República p. } 311\end{array}$ \\
\hline Livro 04 & $\begin{array}{l}\text { Antônio Conselheiro p. } 75 \text {; } \\
\text { Padre Cícero p. } 77 \text {; } \\
\text { Religiões na Luta contra a ditadura de } \\
1964 \text { p. } 283 \text { (Referência em apenas um } \\
\text { parágrafo). }\end{array}$ \\
\hline História - Coleção Elos & Temática de Âmbito Nacional \\
\hline Livro 01 & $\begin{array}{l}\text { Povos Pré-cabralinos p. } 195 \text { (ênfase nos } \\
\text { rituais de Antropofagia). }\end{array}$ \\
\hline Livro 02 & $\begin{array}{l}\text { Igreja e dominação cultural dos povos } \\
\text { indígenas p. } 130\end{array}$ \\
\hline Livro 03 & 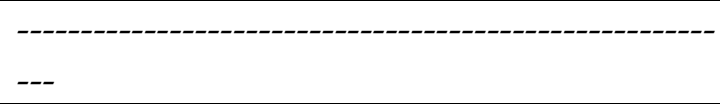 \\
\hline Livro 04 & $\begin{array}{l}\text { Questão Religiosa na Transição do } \\
\text { Império para a República p. 103-104; } \\
\text { Atuação do setor progressista da igreja } \\
\text { católica contra a ditadura civil-militar de } \\
1964 \text { p. } 150 .\end{array}$ \\
\hline
\end{tabular}


Religare, ISSN: 19826605, v.14, n.1, agosto de 2017, p. 131-162.

\begin{tabular}{|l|l|}
\hline Aprendendo com a História & Temática de Âmbito Nacional \\
\hline Livro 01 & $\begin{array}{l}\text { Religiões dos indígenas brasileiros e } \\
\text { religiões africanas p. 65; } \\
\text { Irmandades Mineiras p. 70-71; } \\
\text { Inquisição no Brasil p. 77. }\end{array}$ \\
\hline Livro 02 & $\begin{array}{l}\text { Referência ao Estado republicano laico, } \\
\text { mas não foi explicitado o fim do } \\
\text { padroado p. 09; } \\
\text { Referência da religiosidade em Canudos } \\
\text { p. 11; } \\
\text { Referência a missa da cátedra da Sé } \\
\text { contra a ditadura de 1964 p.105. }\end{array}$ \\
\hline Livro 03 & $\begin{array}{l}\text {------------------------------------------------------ } \\
\text { Livro 04 }\end{array}$ \\
\hline
\end{tabular}

Elaboração do próprio autor

Dados muito semelhantes ao âmbito geral foram encontrados no trato das narrativas de recorte nacional. Pela ocorrência dos mesmos temas demonstrasse a existência do consenso do mercado e a presença de assuntos "canônicos". Porém o que mais chama a atenção são as ausências, as lacunas. Aliás, esta é uma tendência mais acentuada no caso da História pátria, mas já perceptível a nível global. Uma visão panorâmica revelou um retrato muito pálido da dimensão da religiosidade enquanto um fenômeno histórico. Regra geral a partir do século $X X$ a História dos movimentos religiosos em grande parte deixa de ser objeto dos estudos históricos escolares. O interessante é que este é um momento crucial no Brasil. Quando se consolida a diversidade no campo religioso brasileiro o silêncio se estabelece. Clio, a deusa da História, simplesmente emudece. Nenhuma palavra acerca das diferentes possibilidades de acesso a bens simbólicos de salvação.

Neste caso a ausência é eloquente. Talvez aqui possamos socializar algumas hipóteses explicativas. Em seus escritos Chartier (1990; 1994: 17; 2009) adverte para a necessidade de compreensão em separado de dois tipos de 
Religare, ISSN: 19826605, v.14, n.1, agosto de 2017, p. 131-162.

dispositivos que interagem na criação de uma obra, articulados e interdependentes, mas portadores de singularidades, de especificidades. Justamente porque um texto não existe sem um suporte que permita sua legibilidade (CHARTIER, 2002:61-62), há (dispositivos):

“...os que decorrem do estabelecimento do texto, das estratégias de escrita, das intenções do autor; e os dispositivos que resultam da passagem a livro ou a impresso, produzidos pela decisão editorial ou pelo trabalho da oficina, tendo em vista leitores ou leituras que podem não estar de modo nenhum em conformidade com os pretendidos pelo autor." (CHARTIER, 1990, p. 127)

Temos assim, procedimentos decorrentes da criação do texto escrito atrelados a procedimentos oriundos da produção material do livro (CHARTIER, 2008, p. 96 e 97). As análises qualitativas produzidas fazendo uso das noções de dispositivos do texto e da edição parecem ter revelado certas estratégias das editoras, certas decisões editoriais destas empresas. Vejamos o que nos revela um olhar mais aproximado sobre conteúdos referentes à evolução humana. Segue alguns trechos para a nossa discussão:

Evolucionistas e Criacionistas: ciência $X$ religião

Em anos recentes, em alguns estados norte-americanos as autoridades determinaram que fossem excluídas das escolas todas as referências as ideias evolucionistas e que fosse ensinada apenas a teoria criacionista. Isso significa que daí por diante, nesses estados, os estudantes aprendiam que o mundo e a humanidade nasceram de uma criação, que foram feitos por um Criador, segundo a tradição religiosa judaico-cristã, baseada nos textos bíblicos.

Não foi a primeira vez que governos interferiram no debate entre evolucionistas e criacionistas. Trata-se de um debate antigo, que a muito tempo vem colocando frente a frente a ciência e a religião como fontes e instrumentos do conhecimento humano. O conhecimento científico é gerado pela razão, aplicada na investigação e reflexão s obre a natureza e a vida social, enquanto o conhecimento religioso nasce da fé, da crença em princípios, normas e ideais atribuídos a uma entidade divina (Aprendendo com a História, Livro 03, p. 14). 
Primeiramente, de acordo com a Teoria Criacionista formulada secularmente pelos princípios judaico-cristãos, todos os seres existentes no universo definiram-se em função de uma vontade superior. Segundo a bíblia, Deus criou o universo, os planetas, as estrelas, as diferentes espécies de vida em seis dias e reservou o sétimo dia para o seu descanso. (...) Trata-se, portanto, de uma concepção religiosa de universo, não cabendo no nosso estudo o julgamento dessa teoria a partir dos critérios científicos.

Posteriormente, a partir do século XIX, foi formulada a Teoria Evolucionista desenvolvida inicialmente pelos naturalistas Jean Baptiste Lamarck e Charles Darwin. Em especial, Darwin afirmou que todos os seres existentes no universo e suas respectivas manifestações de vida seriam o resultado, na verdade, de uma constante e lenta evolução (História da coleção Elos, Livro 01, p. 50-51).

1.A bíblia diz que Deus criou um único casal, Adão e Eva, ela nada fala sobre a evolução das espécies. Debata estas questões com seus colegas: a ciência está desmentindo a bíblia? Se a ciência diz uma diz uma coisa e a bíblia diz outras, quem está equivocado? É possível que a ciência diga uma coisa, a bíblia diga outra e as duas estejam com a razão? Tudo o que a bíblia diz deve ser aceito ao pé da letra, ou seja, exatamente como está ali, ou há passagens que são simbólicas, que falam de uma fábula mais o principal é o conteúdo moral dela (Nova História Crítica, Livro 01, p. 55, Pergunta 01)?

Nos fragmentos há um tratamento de isonomia para criacionismo e evolucionismo. Talvez contenha um pouco mais de ousadia o trecho da coleção Nova História Crítica que não afirma, mas coloca em forma de pergunta, a possibilidade do relato bíblico representar um mito. Considero aqui a possibilidade de esta postura "respeitosa" frente a debates capitaneados por segmentos religiosos representar uma decisão da equipe técnica responsável pela produção das obras. A aparente posição de suposta neutralidade pode estar indicando uma estratégia editorial. Não assumem a religião como objeto de estudo histórico, mas fazem concessões a setores dos movimentos religiosos. Possivelmente se avalie que ferir sensibilidades poderia diminuir a aceitabilidade do livro didático no mercado. Questões como essa permitem vislumbrar os 
Religare, ISSN: 19826605, v.14, n.1, agosto de 2017, p. 131-162.

ditames da esfera empresarial se sobrepondo aos aspectos pedagógicos. Passemos a situar historicamente o debate instalado.

O criacionismo como crítica a concepção científica da evolução das espécies não é nada novo. Desde o século XIX, com a divulgação da abordagem de Darwin, ele surgiu como resistência, como contra-discurso. De fato, este debate nunca cessou desde então, entretanto, presenciamos no mundo ocidental o reaquecimento das discussões de tempos em tempos. De forma cíclica, quando parece superado, acendem-se os ânimos e novas investidas tem lugar. Citemos o exemplo Norte-Americano, referido inclusive por uma das coleções.

Após significativos avanços na genética e na paleontologia durante a década de 1970, a compreensão da evolução apresentava-se como relativo consenso. O debate criacionista parecia arrefecer, centrando-se nos espaços sociais que lhe são próprios. Na década seguinte, a ultradireita norte-americana ressuscitou a polêmica, apresentando uma versão pseudocientífica do criacionismo. Sem acrescentar nenhum dado novo aos argumentos que defendem a criação divina, lançaram uma elaboração discursiva que se tornou modelar. Para eles, a evolução das espécies seria apenas uma teoria. E teoria em um sentido menor. Como ideia ainda não comprovada. A novidade foi que tanto o criacionismo quanto o evolucionismo foram colocados no campo da crença (GOULD, 1992, p. 253 a 262). Dos EUA para o mundo, essa concepção, hoje muito presente, que se alberga sob a proteção do conciliatório, do politicamente correto, escamoteia a vocação conservadora e a origem dogmática. O interessante é que há uma produção acadêmica que procura desmistificar o edifício retórico construído:

Bem, a evolução é uma teoria. Mas também é um fato. E fatos e teorias são coisas diferentes, e não estágios de uma hierarquia de certeza crescente. Fatos são os dados do mundo. E teorias são as estruturas de ideias que explicas e interpretam os fatos. Os fatos não desaparecem enquanto os cientistas debates teorias rivais que tentam explicá-los. A teoria gravitacional de Einstein substituiu a de Newton, mas as maças não ficaram pairando no ar, à espera da definição. E os seres humanos evoluíram a partir de ancestrais parecidos com símios, quer através do mecanismo 
Religare, ISSN: 19826605, v.14, n.1, agosto de 2017, p. 131-162.

proposto por Darwin, quer através de qualquer outro ainda por descobrir (GOULD, 1992, 254).

Mas o que encontramos nas coleções foi justamente uma apropriação do debate criacionista, apresentando a evolução das espécies como mera "teoria". Compartilhamos a ideia de que a história ensinada nas escolas tem compromissos inegociáveis com o pensamento laico e uma ética republicana, bem como a principal referência do saber escolar precisa ser o conhecimento científico. Não obstante, seria ingenuidade esperar das editoras medidas impopulares. Acreditamos, portanto, que a concessão ao criacionismo represente uma primeira estratégia editorial diante das demandas do campo religioso. Encontramos outras. Por exemplo, o texto narrativo assumir posições teológicas e não históricas.

\begin{abstract}
A Boa Nova
Um povo oprimido. Geste simples, trabalhava a vida inteira para sobreviver: pescadores, carpinteiros, lavadeiras, camponeses. Esmagados pelas botas dos opressores, chicoteados pelos donos de escravos, humilhados pelos estudiosos que serviam aos ricos. Não haveria nenhuma esperança para eles?

O Criador de todas as coisas e da vida não abandona Seus filhos. Entre os humildes, entre esfarrapados, entre os oprimidos, é que Seu filho nasce, vive e ensina. Os primeiros discípulos são todos homens do povo. E é ao povo que Ele se dirige. Foi do povo que Ele ganhou roupa quando tinha frio, foi do povo que Ele recebeu comida e água quando estava faminto e com sede. Somente entre o povo trabalhador, entre os humilhados e ofendidos, é que seria possível multiplicar pães e peixes para que não houvesse necessidade, somente entre os desesperançados é que seria possível superar as doenças e o abandono, somente entre os simples é que seria possível transformar a água em vinho para que houvesse festa. (Nova História Crítica, Livro 01, 197).
\end{abstract}

Esta é uma nítida apropriação da teologia da libertação. Jesus estaria ao lado de uma classe social na História: os oprimidos. A referência a ele como filho de Deus é específica da teologia. Uma abordagem seguindo o pensamento histórico inverteria a proposição. Jesus seria uma figura humana feita divina e não ao contrário, divina que se fez carne. Neste caso a concessão ao campo 
Religare, ISSN: 19826605, v.14, n.1, agosto de 2017, p. 131-162.

religioso não foi pela via da conciliação, mas da adesão implícita a uma determinada linha de pensamento cristão, a uma corrente teológica em particular Foi perceptível também como estratégia presente na esfera do texto a assunção de discursos simpáticos ao grande público consumidor, sem constituir proselitismo, foram quase pró-maioria.

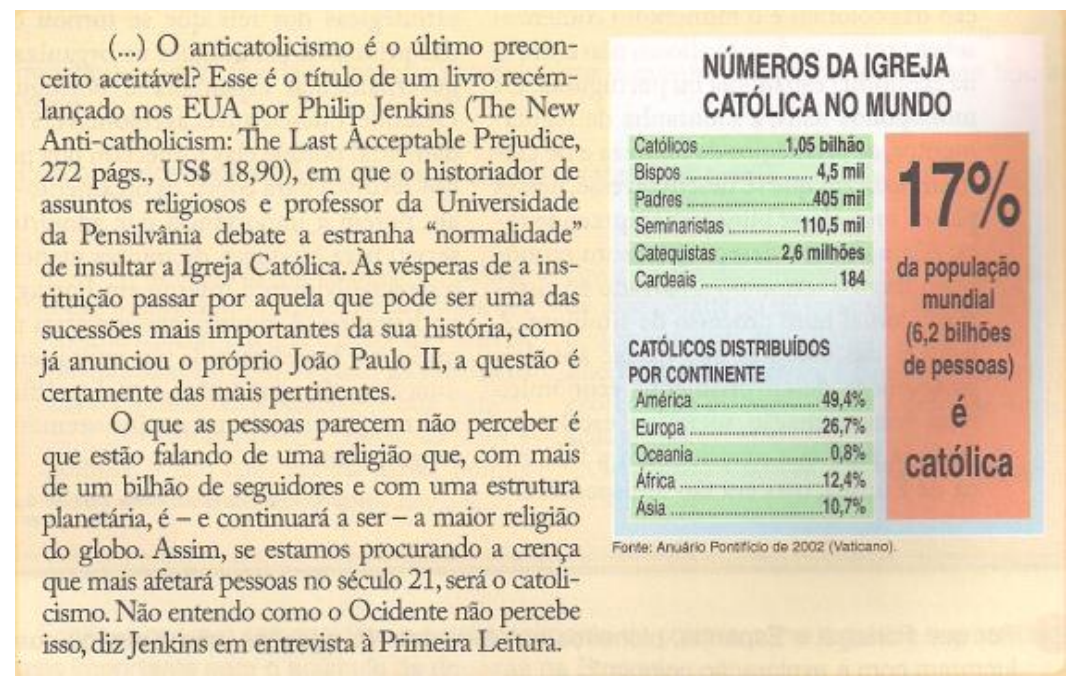

Figura 1 - História da Coleção Elos - livro 2 - p. 94

Possivelmente ocorrências como essa não representem posições prócatólicos, no sentido de fundamentada em vinculações ideológicas de qualquer tipo, mas uma estratégia editorial norteada pela pragmática. Não é interessante para um produto que se quer vendável desagradar abertamente à maioria, seus possíveis consumidores.

Em síntese, as possíveis estratégias editoriais adotadas pelas empresas foram posições consensuais, definições teológicas implícitas, percebidas apenas em um movimento de inferência, discursos simpáticos pró-maioria e o silenciamento completo. Dentre elas, a que compreendo acarretar maiores repercussões trata-se do silêncio estabelecido acerca da diversidade religiosa brasileira. Se para a esfera mundial a diversidade religiosa aparece através de um retrato pobre e embaçado, no âmbito nacional o não-dito é de profunda eloquência. Como conceber que um país marcado por uma rica diversidade religiosa, consolidada historicamente a partir do século XIX, com o advento da república, não tenha essa mesma diversidade abordada enquanto objeto de 
Religare, ISSN: 19826605, v.14, n.1, agosto de 2017, p. 131-162.

estudo de sua História pátria nas escolas da educação básica? Levantamos a hipótese explicativa de que para evitar tomadas de posição explícitas as editoras vêm considerando melhor não tratar das temáticas. Talvez estejam seguindo mais uma vez a lógica pragmática que norteia a esfera empresarial. Sem venda não há lucro. Sem lucro não há sobrevivência da organização. Se posicionar em um campo minado, marcado por fortes disputas simbólicas, como é o caso das questões referentes ao campo religioso, sem dúvida pode estar sendo avaliada como uma estratégia pouco inteligente, arriscada e nada eficaz.

\section{Enfim, o Espiritismo nos livros didáticos de História?}

Diretamente sobre o Espiritismo não encontramos nada. Nenhuma referência foi localizada nas três coleções analisadas. O que equivale a dizer que a História da doutrina espírita não se constituiu em exceção frente ao silêncio existente sobre a diversidade do campo religioso brasileiro. Através dessas obras, os discentes conhecem Luiz XIV, Luiz XVI, Napoleão, Kennedy, Dom Pedro I, Dom Pedro II e até Hitler e Stalin, mas se depender da História ensinada não saberão quem foi Dom Helder Câmera, Irmã Dulce, Mãe Menininha do Cantuá. E porque não, Chico Xavier? Não conhecerão a atuação das comunidades eclesiásticas de base na construção da democracia no Brasil. Também não verão com outros olhos religiões especificamente brasileiras como a Umbanda e o Vale do Amanhecer. Não terão notícias da criação de segmentos eminentemente brasileiros do movimento evangélico, tais como a Assembleia de Deus. Não resta dúvida de que a inserção dessas religiões como objetos de estudo histórico na trilha narrativa seguida pela história escolar poderia trazer contribuições valiosas a formação dos alunos e alunas.

No que tange ao Espiritismo em particular, existe relevância na sua História pelas relações aqui desenvolvidas. No Brasil, como procuramos demonstrar, o espiritismo foi (re) inventado. 
Religare, ISSN: 19826605, v.14, n.1, agosto de 2017, p. 131-162.

Em pouco tempo o espiritismo converteu-se em alternativa religiosa de vanguarda, cujo charme estava em sua singular conjugação entre ciência experimental e fé revelada, associada a um anticlericalismo que agradava a um público de opositores ilustrado do império, notadamente os abolicionistas e republicanos (LEWGOY, 2088, 87)

Sua entrada em terras brasileiras contribui para a construção da diversidade em nosso campo religioso. A luta de suas lideranças para abrigar sua fé no artigo constitucional que garantia liberdade de culto no início da República abriu caminho para outros segmentos. Entretanto, apesar do Espiritismo não figurar no cenário da história escolar, encontramos uma ocorrência em que o texto didático tangencia e até mesmo toca no edifício teórico construído por Kardec. Ela foi localizada na coleção assinada por Mário Schimdt. Se referindo a desigualdade social na civilização indiana, o autor afirmou:

O pior que tudo isso era justificado por aquilo que o Ocidente chamou de religião hinduísta. Os hinduístas acreditam que só o corpo morre. A alma continua viva. Quando a pessoa falece, sua alma vai viver no corpo de um bebê pronto para nascer. A alma acompanha o corpo a vida inteira, mas o bebê cresce, é óbvio, fica adulto e morre. Depois que morre, lá vai a alma de novo migra para outro corpo de bebê. Morrer e nascer em outro corpo se chama reencarnação. Pois aí é que entra o aspecto social: se, durante sua existência aquele corpo, o indivíduo aceitou sua situação (seu carma), não se revoltou contra o fato de pertencer a uma casta inferior, então na próxima encarnação ele reencarnará numa casta superior. Percebeu? Os trabalhadores das castas inferiores não se revoltavam contra as classes dominantes simplesmente por que temiam não subir de casta na encarnação seguinte! Ficavam no fundo do poço da vida porque sonhavam com o elevador social logo após a morte! (Nova História Crítica, Livro 01, p.119-120)

Este me pareceu representar um interessante caso para análise. O texto apresenta simplificações explicativas, fazendo uso das noções de reencarnação e carma para afirmar que a religião hinduísta forneceu elemento ideológico para a manutenção da sociedade de casta. Sem dúvida este é um argumento cabível a todas as grandes religiões do planeta, pois, guardando as devidas especificidades, mas de forma semelhante, apropriações do cristianismo, do 
Religare, ISSN: 19826605, v.14, n.1, agosto de 2017, p. 131-162.

islamismo, do budismo, do judaísmo serviram para a manutenção do status quo. Não obstante, a problemática que gostaríamos de chamar a atenção está na forma descontextualizada do uso dos conceitos. A expressão reencarnação precisa ser historicamente situada. Ela é uma invenção integrante de uma tradição ocidental. Os gregos denominavam o fenômeno de palingenesia ${ }^{8}$. A maioria das correntes hinduístas concebem a volta da alma a um novo corpo a partir da metempsicose ${ }^{9}$, compreensão diferente dos espíritas e de muitas correntes espiritualistas europeias. A compreensão da reencarnação, com uma utilização definida do conceito, centrada no retorno do espírito humano à vida corporal exclusivamente humana não é específica dos hinduístas.

Entre a concepção hindu de metempsicose e a espírita de reencarnação existem pontos de convergências, mas também divergências significativas, verdadeiros abismos. Os distanciamentos não se centram apenas na perspectiva das involuções, admitida pelos orientais e negada pelos espíritas, totalmente evolucionistas. A alma no hinduísmo integra-se após a morte em um todo universal, não mantendo sua individualidade. Já no espiritismo a reencarnação está associada a uma lógica de progresso (AUBRÉE e LAPLANTINE, 2009, p. 88).

\begin{abstract}
Esse princípio da reencarnação não é de forma alguma um elemento acrescido ao conjunto doutrinal dos utopistas do século XIX. Ele decorre diretamente das ideias de liberdade, igualdade e justiça oriundas da revolução francesa. A sociedade industrial dessa época é uma sociedade de iniquidade e opressão, na qual a lei da reencarnação restabelece a ordem e em particular uma moral (idem, idem).
\end{abstract}

Desta forma, a concepção espirita foi fortemente fundamentada em certa matriz de pensamento europeia. É um engano considerá-la um empréstimo aos paradigmas orientais do budismo e do hinduísmo. Foram apropriações do

\footnotetext{
${ }^{8}$ Do grego palin (repetição, de novo) mais genes(e) (nascimento).

${ }^{9}$ Do grego meta (mudança) somada a en(em) e psique (alma). No caso da metempsicose o retorno da alma acontece em corpos de seres humanos e de outros animais indiscriminadamente. Não há uma ideia de evolução, um sentido de progresso.
} 
Religare, ISSN: 19826605, v.14, n.1, agosto de 2017, p. 131-162.

iluminismo do século XVIII, dos filósofos alemães, como Schopenhauer e Goethe. Assim, o universo cultural respirado por Kardec estava impregnado do conceito de reencarnação. Compartilhavam dele principalmente os socialistas utópicos e humanistas, dentre outros. Autores como Hugo, George Sand, Balzac, Eugéne Sue eram reencarnacionistas (AUBRÉE e LAPLANTINE, 2009, p. 90).

Para além destas reflexões conceituais, é preciso lembrar que sem a contextualização histórica necessária, o uso do conceito de reencarnação associado pejorativamente à manutenção das desigualdades sociais, inserido no contexto brasileiro, pode atuar diretamente nos jogos de disputa do campo religioso, sendo elemento a favor das forças que buscam desqualificar as religiões "reencarnacionistas".

Ao que os indícios apontam, talvez dentre as coleções analisadas, a Nova História Crítica seja a única que apresente posições mais claramente situadas do ponto de vista religioso. A julgar pelas apropriações com simpatias declaradas à teologia da libertação e pela forma como o autor se referiu a outros líderes religiosos, como pode ser visto nos exemplos abaixo, a obra traz uma tomada de posição a favor de uma determinada corrente teológica.

Naquela época, um homem que atacasse a igreja podia ser prezo e até queimado na fogueira. Mas, graças a ajuda dos príncipes feudais, Lutero pôde ficar em segurança em um poderoso castelo. Cercado por muralhas e guardas, diante de uma mesa com boa comida e bebida, escrevia divulgando suas ideias (Nova História Crítica, Livro 02, p.165).

O príncipe Sidharta era rico, belíssimo, saldável e inteligente demais. Sua vida parecia ser a melhor do mundo. Vivia em festas, diversões, caçadas (o esporte dos príncipes), banquetes. As mulheres caiam apaixonadas aos seus pés e ele transava com centenas delas. Músicos, pintores e poetas faziam de tudo para diverti-lo. Mas, apesar de mergulhado nos prazeres, Sidharta vivia deprimido. Não encontrava um sentido para a sua vida (Nova História Crítica, Livro 01, p.120).

As afirmativas sobre Lutero ter produzido suas teses "diante de uma mesa com boa comida e bebida" e das relações sexuais de Buda com centenas de 
Religare, ISSN: 19826605, v.14, n.1, agosto de 2017, p. 131-162.

mulheres revelam um olhar marcado por juízos de valor, por uma representação sobre o outro, uma abordagem cunhada sob o signo da diferença. Há aqui riscos de indução a anacronismos e etnocentrismos no pensamento histórico dos discentes durante o processo de recepção da obra, mas essa é uma reflexão para outro momento, em outro lugar.

\section{Considerações Finais}

O exercício de análise acerca da diversidade religiosa nos livros didáticos de História propiciou algumas reflexões interessantes. Identificamos as lacunas existentes sobre a História dos diversos segmentos religiosos, bem como o silenciamento das múltiplas opções construídas no campo religioso brasileiro a partir do Império, mas principalmente do período republicano. Observamos assim que as coleções deixaram de explorar o potencial formativo que o estudo da diversidade religiosa sob o ponto de vista histórico poderia trazer.

Evidentemente, não seria o caso do fenômeno religioso ocupar a centralidade da narrativa histórica escolar. Um estudo aprofundado das religiões e religiosidades é compromisso de outra disciplina, o ensino religioso, que encontra sua contrapartida acadêmica nas licenciaturas em ciências da religião. Não obstante, há uma contribuição especifica da História escolar. Estudar também nessa disciplina o contexto histórico da construção da diversidade poderia contribuir para o reconhecimento das semelhanças e diferenças, poderia ajudar no desenvolvimento de alteridades, na superação da lógica dicotómica baseada no binômio "eu-outro", poderia auxiliar a dirimir proselitismos exacerbados, a conciliar enfrentamentos raivosos engendrados pela demonização do diferente.

As fontes revelaram também alguns dados de certa forma surpreendentes. Encontramos forte permanência do consenso do mercado. Essa constatação nos faz refletir que após duas décadas de avaliações do Programa Nacional do Livro Didático e da ação de setores da sociedade civil, ainda existe um núcleo duro na 
Religare, ISSN: 19826605, v.14, n.1, agosto de 2017, p. 131-162.

configuração clássica da trilha narrativa da História ensinada. Muitas permanências ainda não conseguimos quebrar.

Levantamos hipóteses explicativas acerca da questão do foco do artigo. As equipes responsáveis pelas coleções preferiram não ferir suscetibilidades, o que sem dúvida poderia prejudicar as vendagens. As editoras fazendo concessões a determinados setores dos movimentos religiosos, abriram mão de compromissos com um pensamento cientificamente fundamentado. Em contrapartida, deixaram de tomar ou secundarizaram o fenômeno religioso como objeto de estudo. Considerei que ambos os comportamentos faziam parte de um conjunto de estratégias visando o mesmo fim. Representavam lados de uma mesma moeda. Buscavam ampliar o potencial de circulação das obras.

\section{Referências}

APPLE, Michael. A Política do Conhecimento Oficial: Faz Sentido a Idéia de um Currículo Nacional? In Moreira, Antônio Flávio e Silva, Tomaz Tadeu da (Orgs). Currículo, Cultura e Sociedade. 9ª edição. São Paulo: Cortez, 2006.

ARRIBAS, Célia da Graça. Afinal, Espiritismo é Religião? A doutrina espírita na formação da diversidade religiosa brasileira. São Paulo: Alameda, 2010. AUBRÉE, Marion e LAPLANTINE, François. A Mesa, O Livro e Os Espíritos: gênese, evolução e atualidade do movimento social espírita entre França e Brasil. Maceió: EDUFAL, 2009.

BATISTA, Antônio A.G e ROJO, R.. Livros escolares no Brasil: a produção científica. Em VAL, M.G.C. e MARCUSCHI, B. (Orgs). Livros didáticos de Língua Portuguesa: letramento e cidadania. Belo Horizonte, Autêntica, 2005.

BITTENCOURT, Circe Maria Fernandes. Livros Didáticos de História: práticas e formação docente. In DALBEN, Ângela et all (orgs). Coleção Didática e Prática de Ensino. Belo Horizonte: Autência, 2010.

BRAGANÇA, Anibal. Sobre o Editor: notas para sua história. EM QUESTÃO, Porto Alegre, v. 11, n. 02: p. 219 - 237, jul/dez, 2005.

CASSIANO, Célia Cristina de Figueiredo. O Mercado do Livro Didático no Brasil: da criação do Programa Nacional do Livro Didático (PNLD) á entrada do capital internacional espanhol (1985 - 2007). São Paulo: PUC, 2007. Tese (Doutorado em Educação), PUC, 2007.

CASSIANO, Célia Cristina de Figueiredo. Reconfiguração do mercado editorial brasileiro de livros didáticos no início do século XXI: história das principais 
editoras e suas práticas comerciais. Em Questão, Porto Alegre, v. 11, n. 2, p. 281312, jul/dez, 2005.

CHARTIER, Roger. À Beira da Falésia: a história entre incertezas e inquietude. Porto Alegre: Ed. Universidade/UFRGS, 2002.

CHARTIER, Roger. A História Cultural: entre práticas e representações. Lisboa: DIFEL, 1988.

CHARTIER, Roger. A Ordem dos Livros: leitores, autores e bibliotecas na Europa entre os séculos XIV e XVIII. Brasília: Editora da UNB, 1994.

CHARTIER, Roger. A visão do historiador modernista. In FERREIRA, Marieta de Moraes e AMADO, Janaína (orgs). Usos e Abusos da História Oral. Rio de Janeiro: Editora FGC, 2002.

CHARTIER, Roger. Do livro à leitura. In CHARTIER, Roger (org). Práticas de Leitura. São Paulo: Estação Liberdade, 2009.

CHARTIER, Roger. Inscrever e Apagar: cultura escrita e literatura, séculos XIXVIII. São Paulo: UNESP, 2007.

CHARTIER, Roger. O Mundo como Representação. Revista "Estudos Avançados". São Paulo: 1991.

CHARTIER, Roger. Os Desafios da Escrita. São Paulo: UNESP, 2002.

CHARTIER, Roger. Os Desafios da Escrita. São Paulo: UNESP, 2002.

DAMAZIO, Sylvia F. Da Elite ao Povo: advento e expansão do espiritismo no

Rio de Janeiro. Rio de Janeiro: Bertrand do Brasil, 1994.

GATTI JÚNIOR, Décio. A Escrita Escolar da História: livro didático e ensino no Brasil (1970-1990). Uberlândia: EDUSC/EDUFU, 2004.

GINZBURG, Carlo. Mitos, Emblemas, Sinais: morfologia e História. São Paulo: Companhia das Letras, 2009.

GINZBURG, Carlo. O Fio e os Rastros: verdadeiro, falso, fictício. São Paulo: Companhia das Letras, 2007.

GIUMBELLI, Emerson. O Cuidado dos Mortos: uma história da condenação e legitimação do espiritismo. Rio de Janeiro: Arquivo Nacional, 1997.

LEWGOY, Bernardo. A Transnacionalização do Espiritismo Kardecista Brasileiro: uma discussão inicial. Religião e Sociedade, Rio de Janeiro, 28(1): 84104, 2008.

LEWGOY, Bernardo. Chico Xavier o Grande Mediador: Chico Xavier e a cultura brasileira. Bauru,SP:EDUSC, 2004.

LUCA, Tânia Regina de. Livro Didático e Estado: explorando possibilidades interpretativas. In ROCHA, Helenice Aparecida Bastos at all (orgs). A História na Escola: autores, livros e leituras. Rio de Janeiro: Editora FGV, 2009.

MUNAKATA, Kazumi. Produzindo Livros Didáticos e Paradidáticos. São Paulo: PUC, 1997. Tese (Doutorado em Educação), PUC, 1997.

MUNAKATA, Kazumi.Histórias que os Livros Didáticos Contam, depois que acabou a ditadura no Brasil. In: FREITAS, Marcos César de. Historiografia Brasileira em Perspectiva. São Paulo: Contexto, 2003. 
Religare, ISSN: 19826605, v.14, n.1, agosto de 2017, p. 131-162.

ROCHA, Alexandre Caroli. O Caso Humberto de Campos: autoria literária e mediunidade. (Tese de Doutorado). Doutorado em Teoria e História Literária. Campinas: UNICAMP, 2008.

RYBACK, W. Timothy. A Biblioteca Esquecida de Hitler: os livros que moldaram a vida do Führer. São Paulo: Companhia das Letras, 2009. 